\title{
Bioavailability of quercetin from its aglycone and its glucorhamnoside rutin in lactating dairy cows after intraduodenal administration
}

\author{
A. Gohlke, ${ }^{\star}$ C. J. Ingelmann, ${ }^{*}$ G. Nürnberg, † A. Starke,‡ S. Wolffram,§ and C. C. Metges ${ }^{* 1}$ \\ *Department of Nutritional Physiology "Oskar Kellner," and \\ †Department of Genetics and Biometry, Leibniz Institute for Farm Animal Biology (FBN), 18196 Dummerstorf, Germany \\ $\ddagger C l i n i c$ for Internal Medicine, Faculty of Veterinary Medicine, University of Leipzig, 04103 Leipzig, Germany \\ §Institute of Animal Nutrition \& Physiology, Christian-Albrechts-University of Kiel, 24118 Kiel, Germany
}

\begin{abstract}
Because of their health-promoting properties, flavonoids are used in feed supplements for ruminants, although scientific evidence for their efficacy in vivo is limited. It has been shown recently that bioavailability of quercetin is low after ruminal administration in cows because of degradation by the ruminal microbiota. It is unknown whether quercetin could be absorbed from the small intestine in ruminants if degradation is prevented; therefore, we investigated the bioavailability of quercetin after duodenal administration in 6 German Holstein cows. On $88 \pm 3 \mathrm{~d}$ in milk, each cow received equivalent doses of quercetin $[9,18$, or $27 \mathrm{mg}$ of quercetin equivalents $(\mathrm{QE}) / \mathrm{kg}$ of body weight] either as quercetin aglycone (QA) or as its glucorhamnoside rutin (RU). In addition, 2 control studies with duodenal administration of $\mathrm{NaCl}$ solution $(0.9 \%)$ were conducted per cow to examine concentrations of flavonoids in plasma during regular feeding. Blood samples were collected at defined time intervals over a period of $24 \mathrm{~h}$ before and after administration of the test compounds. A washout period of $2 \mathrm{~d}$ was applied between the runs to avoid possible carryover effects. Concentrations of plasma quercetin aglycone and its metabolites isorhamnetin, tamarixetin, and kaempferol were measured after treatment with glucuronidase/sulfatase by HPLC with fluorescence detection. After administration of RU, levels of plasma quercetin did not increase above baseline, irrespective of dose administered. After duodenal administration of QA, the plasma concentration of QA and its methylated metabolites clearly increased above baseline. The maximal plasma concentrations of total flavonols (about $2 \mathrm{~h}$ after application) increased in a dose-dependent manner but showed high interindividual variability (range 368.8 to $983.3 \mathrm{nmol} / \mathrm{L}$ at 27 $\mathrm{mg}$ of $\mathrm{QE} / \mathrm{kg}$ of body weight) but peak time did not differ. Preadministration baseline values of total flavonols
\end{abstract}

Received October 5, 2012.

Accepted December 13, 2012.

${ }^{1}$ Corresponding author: metges@fbn-dummerstorf.de were reached again 3 to $4 \mathrm{~h}$ after QA administration. The bioavailability of quercetin and its metabolites, as measured by the area under the concentration-time curve, was affected by the quercetin source applied, whereby quercetin from RU was unavailable. Taken together, duodenal administration enhanced bioavailability of QA almost to values previously reported in pigs after oral administration of QA. In contrast to findings in monogastrics or after oral administration in cows, quercetin from RU seems to be unavailable when administered duodenally.

Key words: bioavailability, dairy cow, flavonoid, quercetin

\section{INTRODUCTION}

Because public concern regarding the use of pharmaceuticals in livestock farming is increasing, the application of natural agents, such as flavonoids, as a potential means of improving animal health has become more widespread (Waghorn and McNabb, 2003; Rochfort et al., 2008). Currently, several feed additives for cattle containing flavonoids are commercially available (e.g., http://biopro21.en.ec21.com/ POLI_Queen_1L--1523628_1523752.html; http://www. provimi.com.gr/media/grape_pp_concentrate_-_eng. pdf; http://www.exquim.com/en_UK/areasdenegocias/ nutricionanimal.asp?id $=6445 \& p a g=0 ; \quad$ http: $/ /$ www. biomax.org.uk/citrus-bioflavonoids.php) but independent scientific evaluation of flavonoid effects in ruminants is lacking (Colitti and Stefanon, 2006; Gladine et al., 2007; Cottica et al., 2011; Berger et al., 2012; Balcells et al., accepted). Because all of these products contain mainly crude extracts, it is impossible to determine whether flavonoids or other bioactive compounds are responsible for the observed effects. Quercetin, a frequently investigated flavonoid, is widely distributed in plants and has been shown to exert antiinflammatory and antioxidative effects in vitro and affects glucose and lipid metabolism (Hertog et al., 1992; Middleton et al., 2000; Cermak et al., 2003; de Boer et al., 2005; Reinboth et al., 2010). In nature, quercetin is almost always 
present in glycosylated form (Arts et al., 2004) and one of the most common quercetin glycosides is rutin, in which the disaccharide 6- $o$-L-rhamnosyl-D-glucose is attached to the aglycone. In monogastrics, the bioavailability of quercetin is higher from the aglycone form than from its glucorhamnoside rutin (Hollman et al., 1999; Graefe et al., 2001; Olthof et al., 2000). Although quercetin aglyca pass the intestinal mucosa in the small intestine by passive diffusion (Walgren et al., 1998; Movileanu et al., 2000; Manach et al., 2004), quercetin glycosides are not absorbed until the linkage between aglycone and sugar moiety is cleaved (Arts et al., 2004; Lesser and Wolffram, 2006). Rutin can only be reduced to the aglycone by microbial enzymes and therefore it is absorbed only from the terminal ileum and the large intestine (Manach et al., 1997; Day and Williamson, 2003). Rumen bacteria, such as Clostridium orbiscindens or Eubacterium ramulus, do not only release the aglycone from quercetin glycosides but are also capable of splitting the scaffold of flavonoids (Blaut et al., 2003; Lin et al., 2003; Schoefer et al., 2003; Labib et al., 2004). Therefore, it is assumed that quercetin is degraded by enzymes of rumen microbiota after oral administration, which would considerably lower its bioavailability in cattle. Indeed, Berger et al. (2012) recently reported that the concentration of quercetin in plasma of cows was very low after administration of quercetin aglycone in the rumen.

A prerequisite for quercetin to exert any effect in ruminants is its systemic availability, about which little is known. It is not known whether quercetin can be absorbed from the small intestine in ruminants, in contrast to monogastrics. Therefore, this study is the first to explore the bioavailability of quercetin from quercetin aglycone and rutin after duodenal administration. The hypothesis of this study was that, in bypassing the rumen, bioavailability of quercetin would be increased considerably, to a level similar to that observed in monogastrics. Thus, the objectives were (1) to compare the pharmacokinetics of quercetin and its metabolites after duodenal administration with bioavailability data in pigs published previously (Ader et al., 2000; Cermak et al., 2003) and after ruminal administration (Berger et al., 2012), and (2) to investigate acute effects of quercetin on DMI, milk yield, and plasma concentrations of glucose and NEFA.

\section{MATERIALS AND METHODS}

\section{Animals and Diet}

The experimental procedures were carried out in accordance with the German Animal Protection regulations and were approved by the relevant authorities of the State Mecklenburg-Vorpommern, Germany (Landesamt für Landwirtschaft, Lebensmittelsicherheit und Fischereiwesen Mecklenburg-Vorpommern, Germany).

Six German-Holstein cows $(>10,000 \mathrm{~kg}$ of milk in first lactation) with an average BW of $598.3 \pm 27.6$ $\mathrm{kg}$ were purchased from a local farm (Ahrenshagen, Germany) and fitted with duodenal cannulas in wk 4 of their second lactation. After surgery and during the complete experimental period, the cows were kept on straw bedding in tiestalls. The cows were offered a TMR and tap water for ad libitum intake. The diet composition was calculated for lactating cows according to the recommendations of the German Society of Nutritional Physiology (GfE, 2001). Feed components and chemical composition of the TMR are shown in Table 1. Cows were milked twice daily at 0400 and $1430 \mathrm{~h}$.

\section{Experimental Procedures}

Duodenal cannulas were surgically implanted 4 wk before the start of the bioavailability tests. The PVC duodenal T-cannulas were custom-made by Ludwig Bertram GmbH (Medvet, Laatzen, Germany). The

Table 1. Ingredients and chemical composition (means $\pm \mathrm{SE} ; \mathrm{n}=4$ ) of the diet

\begin{tabular}{lc}
\hline Component & Amount \\
\hline Ingredient (g/kg of DM) & \\
Grass silage & $198.6 \pm 12.56$ \\
Corn silage & $317.3 \pm 7.80$ \\
Barley straw & $19.7 \pm 0.00$ \\
Hay & $19.0 \pm 4.15$ \\
Molassed sugar beet pulp ${ }^{1}$ & $73.5 \pm 6.12$ \\
Canola meal extract $_{\text {Concentrate }}^{2}$ & $11.6 \pm 7.51$ \\
Supplemented minerals $^{3}$ & $342.1 \pm 9.82$ \\
Propylene glycol & \\
Chemical analysis & $8.5 \pm 0.54$ \\
DM (\%) & $9.7 \pm 1.62$ \\
CP (\%) & \\
Crude fat (\%) & $47.71 \pm 1.03$ \\
Crude fiber (\%) & $17.23 \pm 0.34$ \\
ME (MJ/kg of DM) & $3.03 \pm 0.05$ \\
$\mathrm{NE}_{\mathrm{L}}(\mathrm{MJ} / \mathrm{kg}$ of DM) & $14.70 \pm 0.16$ \\
\end{tabular}

${ }^{1}$ Arp, Thordsen, Rautenberg GmbH \& Co KG, Sollerupmühle, Germany: $7.3 \mathrm{MJ}$ of $\mathrm{NE}_{\mathrm{L}} / \mathrm{kg}$ of $\mathrm{DM}, 153 \mathrm{~g}$ of utilizable protein $/ \mathrm{kg}$ of DM.

${ }^{2}$ Concentrate MF 2000 (Vollkraft Mischfutterwerke GmbH, Güstrow, Germany): $33 \%$ extracted soy meal, $20 \%$ corn, $17 \%$ wheat gluten, $8 \%$ extracted rapeseed meal, $5 \%$ sugar beet pulp, $2 \%$ sodium hydrogen carbonate, $1.3 \%$ calcium carbonate, $0.2 \%$ sodium chloride, $8.0 \mathrm{MJ}$ of $\mathrm{NE}_{\mathrm{L}} / \mathrm{kg}$ of DM, $204 \mathrm{~g}$ of utilizable protein $/ \mathrm{kg}$ of DM.

${ }^{3}$ Rinderstolz 9522 lactation (Salvana Tiernahrung GmbH, Sparrieshoop, Germany): $92 \%$ crude ash, $20 \%$ calcium, $5 \%$ phosphorus, $6 \%$ magnesium, $8 \%$ sodium, vitamins.

${ }^{4}$ Propylene glycol USP (Dr. Pieper Technologie- und Produktentwicklung GmbH, Wuthenow, Germany). 
lower disc of the cannulas had an outer diameter of 7.5 $\mathrm{cm}$ and the tube protruding from the intestine was 11 $\mathrm{cm}$ long with an inner diameter of $2 \mathrm{~cm}$. A hard PVC tube was inserted in the rod, which had a thread to close the cannula to the outside.

After overnight feed withdrawal, the surgical area in the right flank was washed, shaved, degreased, and disinfected with iodine (Vetsept, Albrecht, Aulendorf, Germany). Surgery was performed under local anesthesia, consisting of distal paravertebral anesthesia with $80 \mathrm{~mL}$ of $2 \%$ procain (Isocain ad us. vet.; procain hydrochloride $20 \mathrm{mg} / \mathrm{mL}$ and epinephrine $0.025 \mathrm{mg} /$ $\mathrm{mL}$; Selectavet, Weyarn/Holzolling, Germany), and a cutting-line infiltration anesthesia with another $80 \mathrm{~mL}$ of procain. All efforts were made to minimize suffering. A paracostal laparatomy was used to gain entrance to the abdominal cavity. The pylorus, together with the cranial part of the duodenum, was deflected out of the abdomen and the duodenal digesta flow was interrupted with intestinal clamps. The cannulas were implanted in the proximal duodenum approximately $15 \mathrm{~cm}$ behind the pylorus. Using a Cushing suture with absorbable thread (polyglycol acid, Catgut GmbH, Markneukirchen, Germany), the duodenum was closely attached to the rod of the cannula and the intestinal clamps were loosened. Abreast the lower part of the incision, about $5 \mathrm{~cm}$ cranial, a second $3-\mathrm{cm}$-long incision was made in the wall of the abdomen. The rod of the cannula was brought to the exterior through this hole and secured by an additional PVC ring with an outer diameter of $9 \mathrm{~cm}$ and an interrupted suture that attached the skin to the cannula. After administration of $500 \mathrm{~mL}$ of $0.5 \%$ iodine solution (diluted Vetsept, Albrecht) into the abdomen, the laparotomy wound was closed.

Pain medication and prophylactic antibiotic treatment were started before beginning of the surgery. For the next $3 \mathrm{~d}$, each cow was treated with analgesics in form of $25 \mathrm{~mL}$ of Metapyrin (500 mg of metamizol so$\operatorname{dium} / \mathrm{mL}$, Medistar, Ascheberg, Germany) and for 5 d with $60 \mathrm{~mL}$ of Trimethosel (40 mg of trimethoprim and $215.8 \mathrm{mg}$ of sulfonamide sodium $/ \mathrm{mL}$; Selectavet, Weyarn/Holzolling, Germany). In the periods between flavonol administrations, the cannulas were kept closed by a stopcock with a screw thread.

Cows resumed full feed intake $2.5 \mathrm{~d}$ after surgery. Cannulas were cleaned daily during the experimental period. Health status (body temperature, feed intake, milk yield, breathing rate, heart rate, and rumen motility) was monitored daily for 2 wk after surgery.

Before the first bioavailability study, indwelling catheters (Certofix mono, B. Braun Melsungen AG, Melsungen, Germany) were implanted into one jugular vein of the cows when they were between 64 and 83 DIM for frequent blood sampling. Over the experimental period, the catheters were kept patent for approximately $7 \mathrm{~d}$ but were exchanged every other week if necessary. Bioavailability of quercetin was investigated using equimolar amounts of quercetin from 2 different sources: quercetin aglycone (quercetin aglycone dihydrate, QA; Carl Roth GmbH, Karlsruhe, Germany) and the quercetin glucorhamnoside (rutin trihydrate, RU; Carl Roth $\mathrm{GmbH}$ ), each applied at 3 dosages, corresponding to 9,18 , and $27 \mathrm{mg}$ of quercetin equivalents $(\mathbf{Q E}) / \mathrm{kg}$ of BW. Between 0700 and $0800 \mathrm{~h}$ on experimental days, quercetin was administered directly into the duodenal cannula at a rate of $1.8 \mathrm{~g} / \mathrm{min}$ to avoid disturbance of gut motility. Thirty and 15 min before administration and for $24 \mathrm{~h}$ afterward $(30,60,90,120,150,180$, 240, 360, 420, 720, and 1,440 min), blood samples (9 $\mathrm{mL}$ ) were collected in Li-heparin monovettes (Sarstedt, Nümbrecht, Germany). Basal plasma abundance of quercetin and its metabolites were checked twice per cow after intraduodenal administration of the same volume of isotonic $\mathrm{NaCl}$ solution using the same sampling protocol as used for quercetin.

In total, 6 bioavailability tests were conducted per cow in a crossover design, with $\mathrm{QA}$ and RU in 3 equimolar doses in alternate order. Between individual bioavailability studies, a washout period of $2 \mathrm{~d}$ was allowed to avoid possible carryover effects. Over the whole experimental period, milk yield and feed intake were measured daily.

\section{Sample Processing and Analysis}

Dry matter content was determined weekly for grass silage, corn silage, and the TMR. Dry matter, CP, crude fat, and crude fiber in feed samples were determined according to the Weender standard procedure (Naumann and Bassler, 1993). Metabolizable energy and $\mathrm{NE}_{\mathrm{L}}$ were calculated according to the German Society of Nutrition Physiology (GfE, 2009).

Blood samples were immediately centrifuged at 2,000 $\times g$ for $10 \mathrm{~min}$ at $4^{\circ} \mathrm{C}$. Plasma aliquots were stored at $-80^{\circ} \mathrm{C}$ until analysis of flavonols, glucose, and NEFA concentrations in plasma. Analysis of flavonol content in plasma was done by the Institute of Animal Nutrition and Physiology of the Christian-AlbrechtsUniversity (Kiel, Germany). Flavonols were extracted from plasma as described by Egert et al. (2008) and concentrations of quercetin aglycone and its methylated (isorhamnetin, tamarixetin) and dehydroxylated (kaempferol) derivatives were analyzed by HPLC with fluorescence detection as previously described (Ader et al., 2000; Berger et al., 2012). In brief, $980 \mu \mathrm{L}$ of plasma was acidified with $130 \mu \mathrm{L}$ of acetic acid $(0.583 \mathrm{~mol} / \mathrm{L})$, 
spiked with $20 \mu \mathrm{L}$ of rhamnetin (internal standard, 1 $\mathrm{mg} / 20 \mathrm{~mL}$ of methanol; Rotichrom HPLC, Carl Roth $\mathrm{GmbH}$ ) and treated with a mixture of $\beta$-glucuronidase/ sulfatase (from Helix pomatia Type $\mathrm{H}-1$, with final activities of 7,300 and $130 \mathrm{U} / \mathrm{mL}$ for glucuronidase and sulfatase, respectively; Sigma Aldrich Chemie GmbH, Dreieich, Germany) to cleave the ester bonds of glucuronides and sulfates generated through phase II detoxification processes in body tissues. After incubation at $37^{\circ} \mathrm{C}$ for $60 \mathrm{~min}, 3 \mathrm{~mL}$ of acetone was added and the samples were centrifuged at $4^{\circ} \mathrm{C}$ for $45 \mathrm{~min}$ at $3,700 \times g$. The supernatant was evaporated until dryness (partial vacuum at $45^{\circ} \mathrm{C}$, SPD2010 SpeedVac System, Thermo Fischer Scientific GmbH, Dreieich, Germany) and residues were resuspended in $200 \mu \mathrm{L}$ of methanol hydroxide. After $15 \mathrm{~min}$ in an ultrasonic bath, $77.5 \mu \mathrm{L}$ of nanopure $\mathrm{H}_{2} \mathrm{O}$ and $22.5 \mu \mathrm{L}$ of $\mathrm{HCl}$ $(10 \mathrm{~mol} / \mathrm{L})$ were added. Thirty microliters of the final solution was injected by a cooled $\left(4^{\circ} \mathrm{C}\right)$ autosampler (AS-2057 Plus, Jasco, Groß-Umstadt, Germany) onto a C-18 Kromasil 100 column $(250 \times 4 \mathrm{~mm}$, particle size $5 \mu \mathrm{m}$, Jasco) guarded by a precolumn (C-18 Inertsil ODS-2, $10 \times 4 \mathrm{~mm}$, particle size $5 \mu \mathrm{m}$, Jasco). The eluent (flow rate: $1 \mathrm{~mL} / \mathrm{min}$ ) was composed of 0.025 $\mathrm{mol} / \mathrm{L} \mathrm{NaH} \mathrm{PO}_{4}$, acetonitrile, and methanol (68:27:5 $\mathrm{vol} / \mathrm{vol} / \mathrm{vol}$ ). In a postcolumn reactor, the effluent was mixed with $\mathrm{Al}\left(\mathrm{NO}_{3}\right)_{3}$ [flow rate: $0.4 \mathrm{~mL} / \mathrm{min}, 1 \mathrm{mmol} / \mathrm{L}$ in methanol containing $7.5 \%$ (vol/vol) acetic acid] for derivatization, and fluorescence of the flavonol-aluminum complex was measured (excitation wavelength 422 $\mathrm{nm}$, emission wavelength $485 \mathrm{~nm}$; FP920, Jasco). Identification of peaks obtained was performed using the retention times of the standards, which were prepared with pure flavonols (Carl Roth $\mathrm{GmbH}$ ) and treated in the same manner as samples. The detection limit of flavonols was $\leq 10 \mathrm{nmol} / \mathrm{L}$ and the recovery rate was $92 \pm 2 \%$ (mean \pm SEM). Inter- and intraassay CV for quercetin were 7.2 and $0.5 \%$, respectively.

Glucose and NEFA concentrations in plasma were analyzed by the clinic for cattle of the Tierärztliche Hochschule Hannover using an automatic analyzer (Cobas Mira, Hoffman-LaRoche, Basel, Switzerland) and commercial test kits. Plasma NEFA concentrations were determined using an enzymatic colorimetric assay (No. 434-91795, Wako Chemicals GmbH, Neuss, Germany), and plasma glucose concentrations were measured using the hexokinase method (No. A11A01667, ABX Diagnostics, Montpellier, France).

\section{Calculations and Statistical Analysis}

Pharmacokinetic parameters were calculated after correction of each value of the plasma concentrationtime curve for the corresponding basal plasma concen- tration measured $30 \mathrm{~min}$ before flavonol administration. Areas under the plasma curve (AUC) were calculated according to the trapezoidal rule between 0 and 1,440 min. Contributions of single flavonol metabolites (quercetin, isorhamnetin, tamarixetin, and kaempferol) to total plasma flavonols were calculated as AUC proportions of the respective AUC of total flavonols (sum of quercetin, isorhamnetin, tamarixetin, and kaempferol). Maximum plasma flavonol concentrations (Cmax) and the respective time points ( $\mathbf{T} \max )$ were determined directly from the individual plasma concentration-time curves. The apparent terminal plasma elimination half-life (plasma $\mathbf{T}_{1 / 2}$ ) was determined using the PK function of Microsoft Excel by linear regression of the terminal portion of the semi-logarithmic plasma concentration-time profiles as described by Graefe et al. (2001).

Data were statistically evaluated using SAS/STAT 9.3 (SAS Institute Inc., Cary, NC). Plasma concentration-time curves of total flavonols and individual plasma flavonols as well as plasma glucose and NEFA concentrations over $24 \mathrm{~h}$ were analyzed by repeatedmeasures ANOVA (PROC MIXED). The model included the fixed factors flavonoid type (QA, RU), dose (0, 9, 18, $27 \mathrm{mg}$ of $\mathrm{QE} / \mathrm{kg}$ of $\mathrm{BW}$ ), and the repeated factor time of blood sampling relative to the duodenal administration, as well as the interactions flavonoid type $\times$ dose, flavonoid type $\times$ time, dose $\times$ time, flavonoid type $\times$ dose $\times$ time, and individual cow as random effect. Cow BW, DIM, daily DMI, and milk yield, plasma AUC, Tmax, Cmax, and plasma $\mathrm{T}_{1 / 2}$ of single flavonols and total flavonols were also evaluated using the mixed model with the factors flavonoid type and dose and the interaction flavonoid $\times$ dose.

Effects were considered significant at $P \leq 0.05$, and discussed as a trend at $0.05<P \leq 0.10$. Differences between treatments were identified using the TukeyKramer test. Data are presented as least squares means $(\mathrm{LSM}) \pm$ standard errors of the mean (SEM).

\section{RESULTS}

\section{Bioavailability Studies}

Body weight was similar among cows and did not change during the bioavailability studies (Table 2). Twenty-four-hour plasma samples taken during the control studies after administration of physiologic saline showed the presence of quercetin and its metabolites isorhamnetin and kaempferol in plasma at relatively steady amounts, whereas tamarixetin could not be detected. The concentrations of the individual flavonols were within the range of or below the detection limit (Figure 1).

Plasma flavonol concentrations and the pharmacokinetic variables AUC and Cmax were affected by 
flavonoid type, dose, and time of blood sampling ( $P$ $<0.01$; Table 2). Duodenal administration of QA at doses of 9 and $18 \mathrm{mg}$ of $\mathrm{QE} / \mathrm{kg}$ of $\mathrm{BW}$ resulted in increased plasma concentrations of total flavonols after $1.5 \mathrm{~h}(P<0.01)$. After administration of the highest dose $(27 \mathrm{mg}$ of $\mathrm{QE} / \mathrm{kg}$ of $\mathrm{BW})$, concentrations of total flavonols were already increased after $1 \mathrm{~h}(P<0.01$; Figure 2). Maximum concentrations (Cmax) of total flavonols were affected by flavonoid type and increased dose dependently, as was Tmax, which was between 105 and $125 \mathrm{~min}$ (overall LSM $113 \pm 6 \mathrm{~min}$ ) after duodenal QA administration (Table 2). Although interindividual variability of Cmax was high at each dosage of QA (396 to $983 \mathrm{nmol} / \mathrm{L}$ at the highest dosage administered), Cmax was higher with the dose of $27 \mathrm{mg}$ than $9 \mathrm{mg}$ of $\mathrm{QE} / \mathrm{kg}$ of BW (Table 2). By $3 \mathrm{~h}$ after administration of the lowest QA dose, total plasma flavonol concentrations returned to (preadministration) baseline values $(P=0.28)$, whereas for 18 and $27 \mathrm{mg}$ of $\mathrm{QE} / \mathrm{kg}$ of $\mathrm{BW}$, baseline values were reached $4 \mathrm{~h}$ after administration $(P=0.76$ and 0.47$)$. For individual plasma flavonols, baseline values for kaempferol, quercetin, tamarexitin, and isorhamnetin were reached 150, 180, 180, and 240 min, respectively, after administration of the lowest dose, and were reached 240, 240, 240, and 360 min after administration of the highest dose of QA.

The AUC of plasma total flavonols increased in a dose-dependent manner after administration of QA $(P$ $<0.01$; Table 2). Based on AUC values after QA administration, quercetin was the main flavonol found in plasma, accounting for $82 \%$ of total flavonols measured, independent of the dose applied $(P>0.9$; Figure 3$)$. The proportion of the methylated metabolite isorhamnetin was an order of magnitude lower than that of quercetin (9\%). Tamarixetin and kaempferol accounted for only 4 and $6 \%$ of total plasma flavonols, respectively. The relative plasma concentrations of quercetin as well as the proportion of its metabolites (sum of isorhamnetin, tamarixetin, and kaempferol) changed with time $(P<$ 0.01). After QA administration, the relative proportion of plasma quercetin (\% of total flavonols) was highest at $110 \mathrm{~min}$ and decreased steadily until $6 \mathrm{~h}$ after duodenal administration (Figure 4).

In contrast to results for QA, duodenal administration of RU did not result in a significant increase of plasma flavonol concentrations over baseline values (Figure 5), and the proportion of the individual flavonols in plasma did not change with time (data not shown).

\section{Effects of Quercetin on Performance and Metabolism}

Duodenal administration of QA or RU had no effects on daily DMI (average $21.3 \pm 0.2 \mathrm{~kg}$ ) or milk yield (average $39.5 \pm 0.6 \mathrm{~kg}$ ) on the day of administration or the next day $(P>0.9)$. Plasma concentrations of glucose and NEFA were not significantly altered within $24 \mathrm{~h}$ of the duodenal administration of QA (Figure 6).

\section{DISCUSSION}

In bypassing the rumen by the use of duodenal cannulas to avoid microbial degradation, we explored the bioavailability of quercetin from its aglycone form and from rutin in lactating dairy cows. Although quercetin aglycone was absorbed after duodenal administration, the quercetin derived from rutin appeared not to reach the systemic circulation. We anticipated that duodenal administration would result in similar pharmacokinetics for QA and rutin, as has been reported for monogastrics. Indeed, after duodenal administration of comparable doses of QA in cows, the calculated pharmacokinetic variables Cmax and Tmax for quercetin aglycone were in the same range as found after oral QA administration in pigs (Cermak et al., 2003: $50 \mathrm{mg}$ of QA $/ \mathrm{kg}$ of $\mathrm{W}:$ Cmax $=1,190 \mathrm{nmol} / \mathrm{L}, \operatorname{Tmax}=120$ min; Lesser et al., 2004: $10 \mathrm{mg}$ of QA $/ \mathrm{kg}$ of BW: Cmax $=518 \mathrm{nmol} / \mathrm{L}, \operatorname{Tmax}=102 \mathrm{~min})$. Interestingly, after duodenal administration of QA at $27 \mathrm{mg} / \mathrm{kg}$ in cows, the AUC of the plasma concentration-time curve of total flavonols $(95.2 \mu \mathrm{mol} / \mathrm{L})$ was only $30 \%$ of the AUC in pigs normalized for the same dose (Cermak et al., 2003: $50 \mathrm{mg}$ of $\mathrm{QA} / \mathrm{kg}$ of $\mathrm{BW}: \mathrm{AUC}=520 \mu \mathrm{mol} / \mathrm{L} \times$ min; Lesser et al., 2004: $10 \mathrm{mg}$ of $\mathrm{QA} / \mathrm{kg}$ of BW: AUC $=117 \mu \mathrm{mol} / \mathrm{L} \times \min )$. This implies that quercetin in cows is eliminated or metabolized faster or absorbed less efficiently from the small intestine than in pigs, although the half-life of quercetin calculated in this study $(3.3 \mathrm{~h})$ was comparable to that calculated in pigs (3.8 h; Ader et al., 2000). As expected, AUC and Cmax were more than 10 times higher after duodenal administration of QA than after intraruminal administration at a similar dose (Berger et al., 2012). Compared with bioavailability parameters after intraruminal administration of rutin, Cmax, AUC, and Tmax values were only slightly higher after duodenal administration of QA if normalized for dose (Berger et al., 2012). Based on these data, rutin might be a rumen-stabilized form of quercetin. Thus, the higher Cmax after duodenal administration might suggest that the rumen microbiota not only cleaved the $\beta$-glycosidic bond of rutin to yield rutinose and quercetin, but also partially degraded the liberated quercetin to phenolic acid, which might have lowered the systemic availability of quercetin from rutin. The higher AUC after duodenal administration might be due to slower absorption than after intraruminal administration, as suggested by the lower Tmax of 42 min after administration into the rumen (Berger et al., 2012). 
Table 2. Pharmacokinetic parameters in dairy cows after duodenal administration of 3 doses of quercetin (Q; 9, 18, and 27 mg/kg of BW) as equimolar amounts of the flavonols quercetin aglycone dihydrate and rutin trihydrate ${ }^{1}$

\begin{tabular}{|c|c|c|c|c|c|c|c|c|c|c|c|}
\hline \multirow[b]{2}{*}{ Item } & \multirow{2}{*}{$\frac{\text { Control }}{0}$} & \multicolumn{3}{|c|}{ Quercetin aglycone } & \multicolumn{3}{|c|}{ Rutin trihydrate } & \multirow[b]{2}{*}{ SEM } & \multicolumn{3}{|c|}{$P$-value } \\
\hline & & 9 & 18 & 27 & 9 & 18 & 27 & & Flavonol & Dose & Flavonol $\times$ Dose \\
\hline DIM (d) & 86.8 & 87.3 & 87.3 & 88.8 & 87.3 & 87.3 & 88.8 & 3.3 & 1 & $>0.9$ & 1 \\
\hline BW (kg) & 603.9 & 602.8 & 601.5 & 606.3 & 602.0 & 605.8 & 600.8 & 8.6 & $>0.9$ & $>0.9$ & $>0.9$ \\
\hline \multicolumn{12}{|c|}{$\operatorname{Cmax}^{2}(\mathrm{nmol} / \mathrm{L})$} \\
\hline $\mathrm{Cmax}_{\text {Total }}$ & $3.9^{\mathrm{c}}$ & $406.9^{\mathrm{b}}$ & $573.4^{\mathrm{ab}}$ & $635.8^{\mathrm{a}}$ & $27.1^{\mathrm{c}}$ & $18.2^{\mathrm{c}}$ & $19.1^{\mathrm{c}}$ & 50.2 & $<0.01$ & $<0.01$ & $<0.01$ \\
\hline $\operatorname{Cmax}_{\mathrm{Q}}$ & $2.9^{\mathrm{c}}$ & $350.0^{\mathrm{b}}$ & $504.1^{\mathrm{ab}}$ & $555.5^{\mathrm{a}}$ & $21.9^{\mathrm{c}}$ & $14.8^{\mathrm{c}}$ & $17.3^{\mathrm{c}}$ & 44.1 & $<0.01$ & $<0.01$ & $<0.01$ \\
\hline $\operatorname{Cmax}_{K}$ & $1.3^{\mathrm{c}}$ & $18.2^{\mathrm{ac}}$ & $19.5^{\mathrm{ab}}$ & $31.8^{\mathrm{a}}$ & $5.5^{\mathrm{bc}}$ & $2.3^{\mathrm{c}}$ & $2.7^{\mathrm{bc}}$ & 4.2 & $<0.01$ & $<0.01$ & $<0.01$ \\
\hline $\operatorname{Cmax}_{\mathrm{I}}$ & $0.6^{\mathrm{b}}$ & $27.7^{\mathrm{a}}$ & $37.0^{\mathrm{a}}$ & $34.9^{\mathrm{a}}$ & $1.8^{\mathrm{b}}$ & $1.8^{\mathrm{b}}$ & $1.3^{\mathrm{b}}$ & 3.2 & $<0.01$ & $<0.01$ & $<0.01$ \\
\hline \multicolumn{12}{|l|}{$\operatorname{Tmax}^{3}(\min )$} \\
\hline $\operatorname{Tmax}$ & - & $105^{\mathrm{b}}$ & $110^{\mathrm{ab}}$ & $125^{\mathrm{a}}$ & - & - & - & 6.1 & - & 0.058 & - \\
\hline $\operatorname{Tmax}_{Q}$ & - & 110 & 110 & 125 & - & - & - & 5.9 & - & 0.168 & - \\
\hline $\operatorname{Tmax}_{K}$ & - & $105^{\mathrm{b}}$ & $120^{\mathrm{ab}}$ & $130^{\mathrm{a}}$ & - & - & - & 8.3 & - & 0.080 & - \\
\hline $\operatorname{Tmax}_{\mathrm{I}}$ & - & 115 & 115 & 135 & - & - & - & 7.2 & - & 0.173 & - \\
\hline \multicolumn{12}{|c|}{$\operatorname{AUC}^{4}(\mu \mathrm{mol} / \mathrm{L} \times \min )$} \\
\hline $\mathrm{AUC}_{\text {Total }}$ & $2.2^{\mathrm{c}}$ & $50.7^{\mathrm{b}}$ & $80.0^{\mathrm{ab}}$ & $95.2^{\mathrm{a}}$ & $8.3^{\mathrm{c}}$ & $7.9^{\mathrm{c}}$ & $6.1^{\mathrm{c}}$ & 8.6 & $<0.01$ & $<0.01$ & $<0.01$ \\
\hline $\mathrm{AUC}_{\mathrm{Q}}$ & $1.3^{\mathrm{c}}$ & $40.8^{\mathrm{b}}$ & $66.0^{\mathrm{ab}}$ & $76.1^{\mathrm{a}}$ & $5.0^{\mathrm{c}}$ & $6.1^{\mathrm{c}}$ & $4.0^{c}$ & 6.2 & $<0.01$ & $<0.01$ & $<0.01$ \\
\hline $\mathrm{AUC}_{\mathrm{K}}$ & $0.6^{\mathrm{c}}$ & $3.0^{\mathrm{abc}}$ & $4.5^{\mathrm{ab}}$ & $6.3^{\mathrm{a}}$ & $2.2^{\mathrm{bc}}$ & $1.2^{\mathrm{bc}}$ & $1.8^{\mathrm{bc}}$ & 0.9 & $<0.01$ & $<0.01$ & $<0.05$ \\
\hline $\mathrm{AUC}_{\mathrm{I}}$ & $0.3^{\mathrm{b}}$ & $5.0^{\mathrm{b}}$ & $6.6^{\mathrm{a}}$ & $8.7^{\mathrm{a}}$ & $1.1^{\mathrm{b}}$ & $0.6^{\mathrm{b}}$ & $0.5^{\mathrm{b}}$ & 1.3 & $<0.01$ & $<0.01$ & $<0.01$ \\
\hline \multicolumn{12}{|l|}{ Plasma $\mathrm{T}_{1 / 2}{ }^{5}(\mathrm{~h})$} \\
\hline Plasma $\mathrm{T}_{1 / 2}$ & - & 2.9 & 4.8 & 3.8 & - & - & - & 1.0 & - & 0.393 & - \\
\hline Plasma $\mathrm{T}_{1 / 2 \mathrm{Q}}$ & - & 2.8 & 3.8 & 3.3 & - & - & - & 0.8 & - & 0.661 & - \\
\hline
\end{tabular}

${ }^{\mathrm{ac}}$ Means in a row without a common letter differ significantly, $P \leq 0.05$.

${ }^{1}$ Values are LSM \pm pooled SEM; $\mathrm{n}=6$.

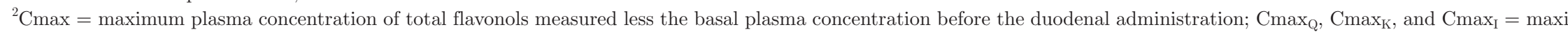
mum plasma concentration of quercetin aglycone, kaempferol, and isorhamnetin, respectively, measured less the basal plasma concentration before the duodenal administration.

${ }^{3} \mathrm{Tmax}=$ time until Cmax was reached; $\operatorname{Tmax}_{Q}, \mathrm{Tmax}_{K}, \mathrm{Tmax}_{\mathrm{I}}=$ time until $\mathrm{Cmax}_{\mathrm{Q}}, \mathrm{Cmax}_{\mathrm{K}}$, and $\mathrm{Cmax}_{\mathrm{I}}$ were reached, respectively.

${ }^{4} \mathrm{AUC}_{\text {Total }}=$ area under the plasma concentration time-curve $(\mathrm{AUC})$ of total flavonols from time 0 to 1,440 min, calculated according to the trapezoidal rule; $\mathrm{AUC}_{\mathrm{Q}}, \mathrm{AUC}_{\mathrm{K}}, \mathrm{AUC}_{\mathrm{U}}$ $=\mathrm{AUC}$ of quercetin aglycone, kaempferol, and isorhamnetin, respectively, from time 0 to 1,440 min, calculated according to the trapezoidal rule.

${ }^{5} \mathrm{PlasmaT}_{1 / 2}=$ terminal plasma half-life of total flavonols; Plasma $_{1 / 2 \mathrm{Q}}=$ terminal plasma half-life of quercetin aglycone. 


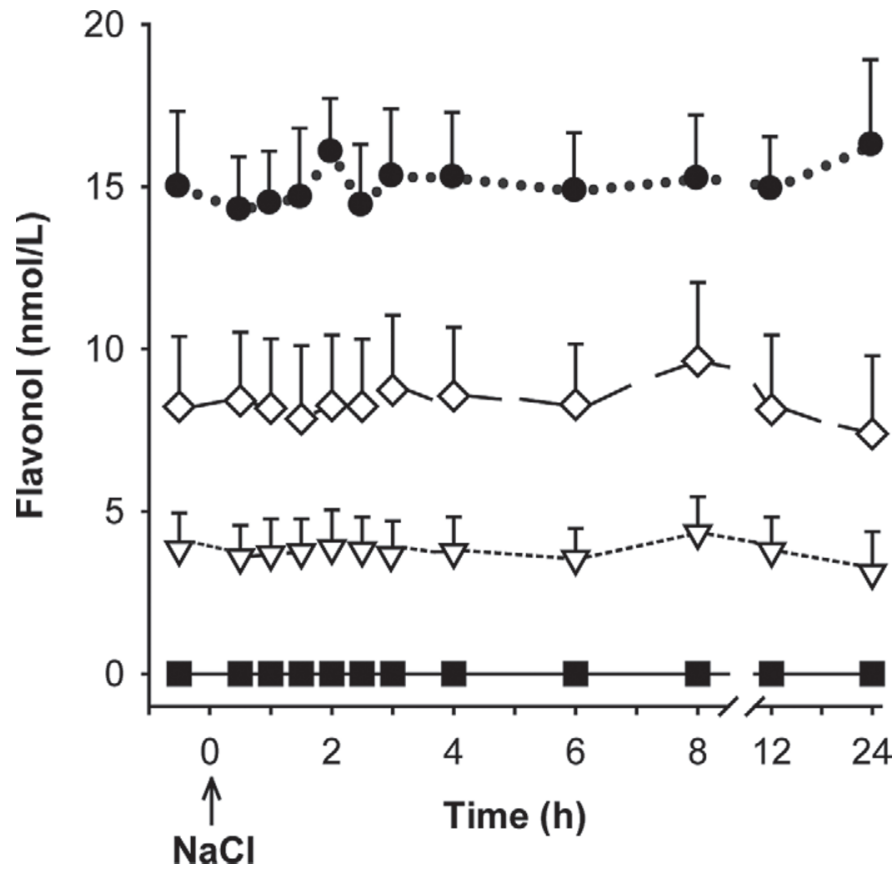

Figure 1. Plasma concentration-time curves of flavonols quercetin $(\bullet)$, kaempferol $(\diamond)$, isorhamnetin $(\nabla)$, and tamarixetin $(\boldsymbol{\square})$ during control studies ( $\mathrm{NaCl}$ administration). Values are $\mathrm{LSM} \pm \mathrm{SEM}$ of 6 cows.

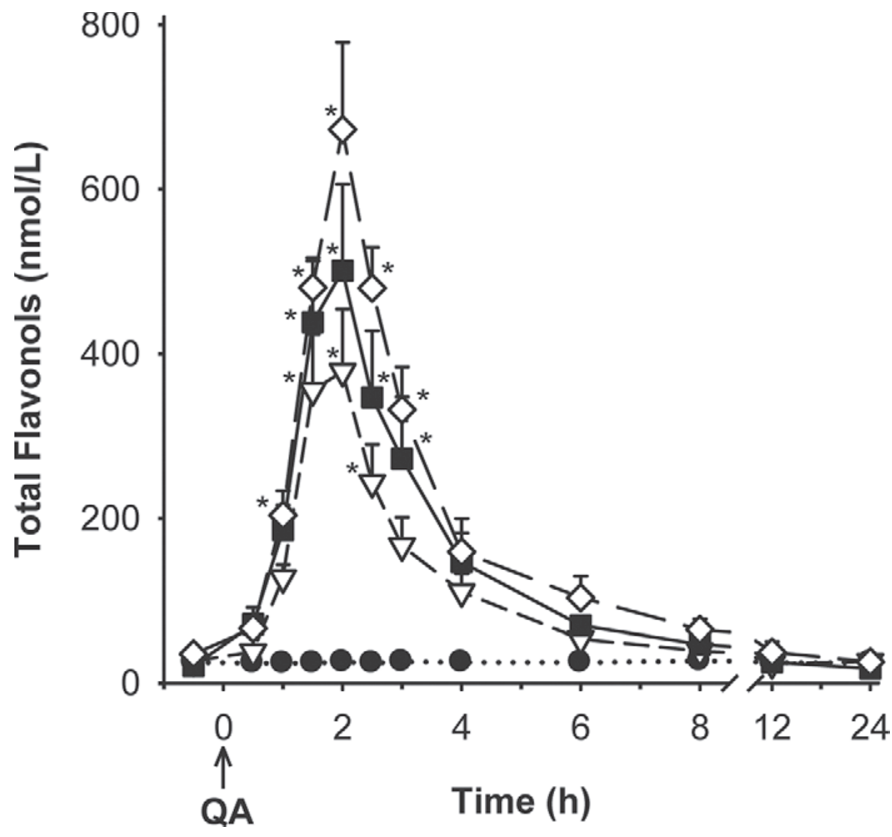

Figure 2. Plasma concentration-time curves of total flavonols after administration of 3 doses of quercetin: $9(\nabla), 18(\boldsymbol{\square})$, and $27(\diamond) \mathrm{mg}$ of quercetin equivalent $(\mathrm{QE}) / \mathrm{kg}$ of $\mathrm{BW}$ as quercetin aglycone dihydrate (QA) compared with the control $(\mathrm{NaCl}$ solution, $\bullet$ ). Values are LSM \pm SEM of 6 cows for the lower doses (9 and $18 \mathrm{mg}$ of $\mathrm{QE} / \mathrm{kg}$ of BW) and 5 cows for the highest dose administered $(27 \mathrm{mg}$ of $\mathrm{QE} / \mathrm{kg}$ of BW); ${ }^{*} P<0.001$ versus preadministration plasma concentrations. Flavonoid type, dose, time, flavonoid type $\times$ dose, flavonoid type $\times$ time, dose $\times$ time, flavonoid type $\times$ dose $\times$ time were significant $(P<0.001)$.

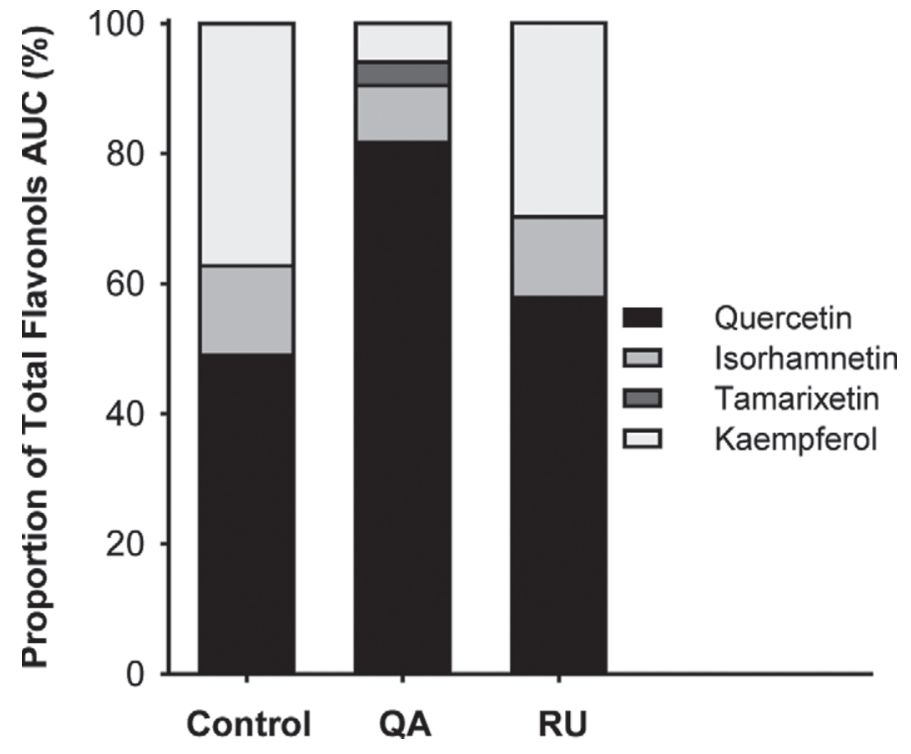

Figure 3. Proportion of single flavonols (quercetin, isorhamnetin, tamarixetin, and kaempferol) in plasma after administration of quercetin aglycone dihydrate (QA), rutin trihydrate (RU), or $\mathrm{NaCl}$ (control) derived from total flavonol area under the curve (AUC) values. Proportions were irrespective of dosage of QA and RU, respectively.

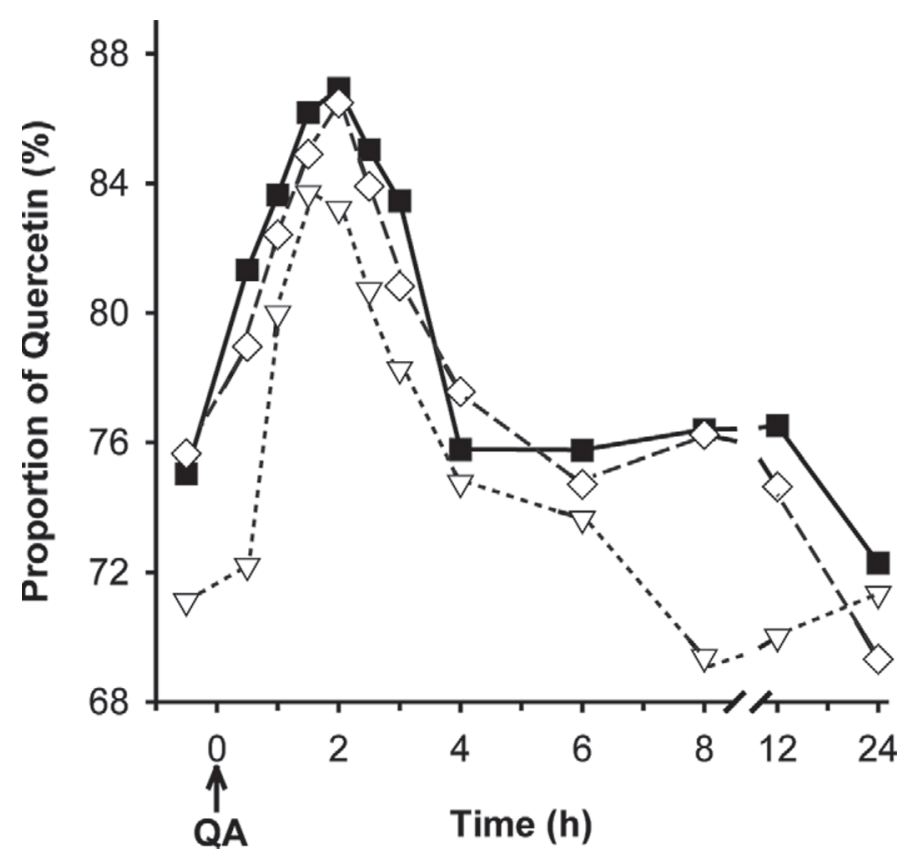

Figure 4. Plasma proportion of quercetin ( $\%$ of total flavonols)time curves after administration of quercetin aglycone dihydrate (QA) in 3 doses: $9(\nabla), 18(\square)$, and $27(\diamond) \mathrm{mg}$ of quercetin equivalents $(\mathrm{QE}) / \mathrm{kg}$ of BW. Values are LSM \pm SEM of 6 cows. Error bars were omitted for clarity. 


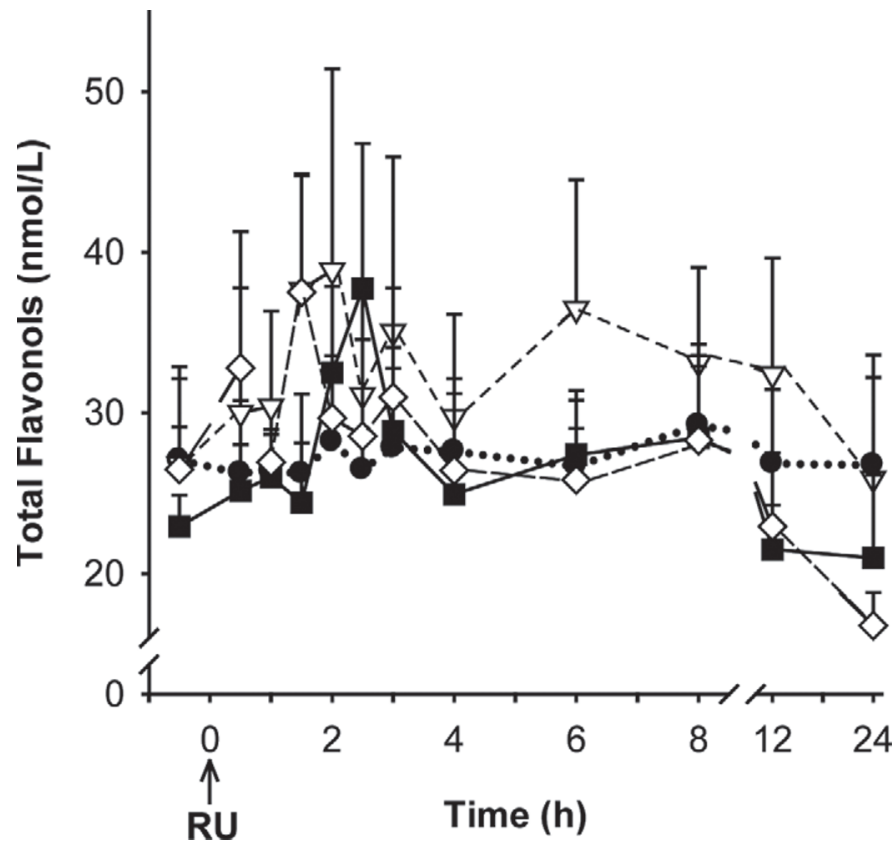

Figure 5. Plasma concentration-time curves of total flavonols after administration of 3 doses of quercetin: $9(\nabla), 18(\mathbf{\square})$, and $27(\diamond)$ $\mathrm{mg}$ of quercetin equivalents $(\mathrm{QE}) / \mathrm{kg}$ of $\mathrm{BW}$ as rutin trihydrate (RU) compared with the control $(\mathrm{NaCl}, \bullet)$. Note the difference in scaling of the y-axis compared with quercetin aglycone as presented in Figure 4. Values are LSM \pm SEM of 6 cows. For significant factors, see Figure 2.

The high interindividual variability in Cmax has also been described in humans and is attributed to a particular polymorphism for intestinal transporters or enzymes (Manach et al., 2005; Egert et al., 2008). Regarding total plasma flavonols in cows, the dominance of quercetin conjugates in plasma and the relatively low concentrations of the methylated metabolites isorhamnetin and tamarixetin after QA administration were also in accordance with findings in humans and pigs (Ader et al., 2000; Egert et al., 2008), whereas more than two-thirds of total flavonols in plasma can be methylated in rats (de Boer et al., 2005).

In contrast to that from QA, the availability of quercetin from RU appears to be negligible in dairy cows when the rumen is bypassed. In monogastric species, absorption of quercetin from rutin compared with quercetin aglycone is delayed because rutinose has to be cleaved by bacterial $\alpha$-rhamnosidase first in the large intestine. Therefore, absorption is restricted to the large intestine, which explains the lower AUC and Cmax and higher Tmax values found in pigs and other monogastric animals (Cermak et al., 2003; Reinboth et al., 2010). One factor contributing to the lack of absorption of quercetin from RU when administered duodenally in dairy cows might be differences between the microbiota of the terminal ileum and large intestine in ruminants and pigs. a)
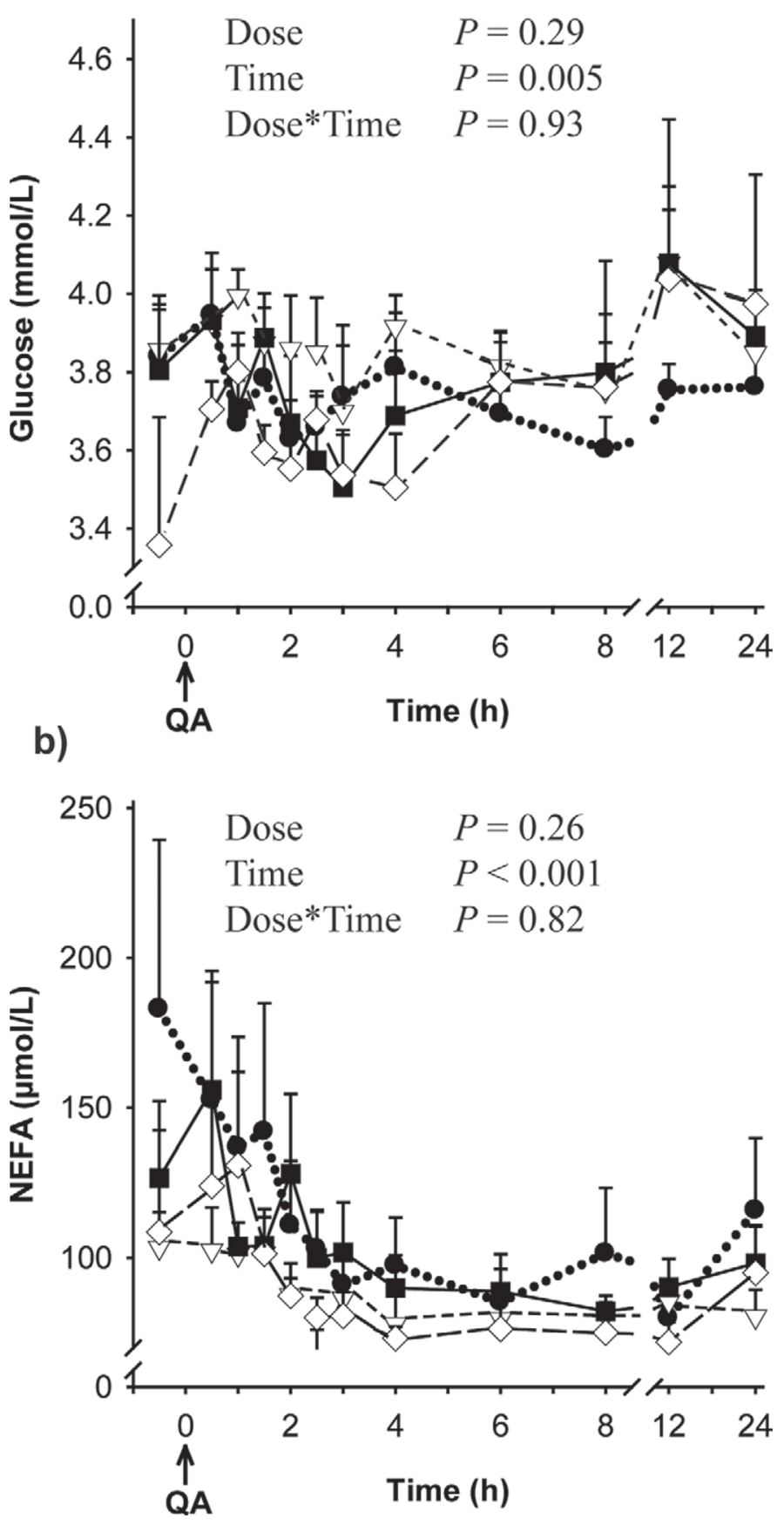

Figure 6. Plasma concentration-time curves of (a) glucose, and (b) NEFA after administration of 3 doses of quercetin: $9(\nabla), 18(\mathbf{\square})$, and $27(\diamond) \mathrm{mg}$ of quercetin equivalents $(\mathrm{QE}) / \mathrm{kg}$ of $\mathrm{BW}$ as quercetin aglycone dihydrate $(\mathrm{QA})$ compared with the control $(\mathrm{NaCl}, \bullet)$. Values are LSM \pm SEM of 6 cows. Dose and dose $\times$ time were not significant $(P>0.2)$; time was significant $(P<0.01)$.

Although strains of rumen bacteria capable of liberating quercetin aglycone from rutin have been characterized, no data on $\alpha$-rhamnosidase activity in the hindgut of cattle is available, to the best of our knowledge. Never- 
theless, it has been shown that bacterial populations of rumen and large intestine differ greatly in cows (Cheng et al., 1969; Michelland et al., 2009; Frey et al., 2010). However, not only the lack of quercetin aglycone release from RU but also the extensive microbial metabolism of quercetin to phenolic acids could explain the lack of absorption of quercetin after duodenal RU administration. Cermak and Breves (2006) suggested that the microbial activity degrading the flavonol structure could be higher than the activity of $\alpha$-rhamnosidases in the cecal fluid of slaughtered pigs.

The negligible appearance of quercetin aglycone from rutin in plasma of cows after duodenal application, compared with that in pigs, might also be explained by differences in the retention time of digesta. In cattle, small and large intestinal retention time of digesta accounted only for 24 to $30 \%$ of total mean retention time, whereas in the large intestine of pigs, it was $87 \%$ of total mean retention time (Mambrini and Peyraud, 1997; Wilfart et al., 2007). Intestinal retention time in cattle has been shown to be lower with higher DMI. In our study, a daily DMI of $21 \mathrm{~kg}$ translated to a mean intestinal retention time of approximately 8 to $9 \mathrm{~h}$; this amounts to $<3.5 \mathrm{~h}$ retention in the large intestine, where degradation of rutin to quercetin is assumed to happen (Pond et al., 1988; Poore et al., 1991; Mambrini and Peyraud, 1997). These values are much lower than those in pigs, where intestinal retention time varies between 28 and $49 \mathrm{~h}$ (Pond et al., 1988; Poore et al., 1991; Mambrini and Peyraud, 1997; Wilfart et al., 2007). We assume that low hydrolysis of rutin, due to a short retention time in the large intestine, combined with rapid degradation of the released quercetin aglycone could explain the low bioavailability of quercetin from rutin administered to the duodenum observed in cows compared with pigs.

The occurrence of plasma concentrations of quercetin, isorhamnetin, and kaempferol, albeit low, in cows receiving the $\mathrm{NaCl}$ treatment (control) suggests intake of flavonoids with the basal diet. Several studies reported the polyphenolic composition of permanent pastures or various kinds of forages (Fraisse et al., 2007; Besle et al., 2010; Reynaud et al., 2010). Besle et al. (2010) found $0.68 \mathrm{~g}$ of quercetin and $0.36 \mathrm{~g}$ of kaempferol $/ \mathrm{kg}$ of DM in ryegrass silage. Ryegrass is widely distributed and native to Europe and therefore might have been part of the grass silage fed in this study. Unfortunately, the flavonol content of the feed was not measured but we estimated a maximal intake of $3 \mathrm{~g}$ of quercetin from grass silage in the present study, based on the data of Besle et al. (2010). Because the DMI of cows was not affected by flavonol administration, and flavonol concentrations in plasma during the control studies were very low compared with those achieved by supplement- ing QA ( $\sim 20 \mathrm{~g} /$ cow at maximal dose), the influence of flavonol intake from the basal diet was assumed to be low.

It has been claimed that feedstuffs rich in phenolic compounds could affect milk yield and quality but the effect of dietary polyphenols has rarely been investigated in ruminants (O'Connell and Fox, 2001). Ewes fed Lotus corniculatus, a forage plant rich in proanthocyanidins ( $27 \mathrm{~g}$ of extractable condensed tannin $/ \mathrm{kg}$ of DM and $8 \mathrm{~g}$ of bound condensed tannin $/ \mathrm{kg}$ of $\mathrm{DM}$ ), showed increased milk yields, especially in late lactation (Wang et al., 1996). Furthermore, sylimarin (10 g/d), a milk thistle extract consisting mainly of flavonol-lignans, has been shown to increase milk yield and lactation performance if administered for $25 \mathrm{~d}$ around calving in dairy cows (Tedesco et al., 2004). However, our finding that a one-time administration did not affect milk yield needs to be verified; in particular, the effects of quercetin after longer term administration need to be studied.

Quercetin supplementation has been shown to affect glucose absorption and metabolism. For example, it reduced blood glucose levels in diabetic rats injected with $10 \mathrm{mg}$ of $\mathrm{QA} / \mathrm{kg}$ of BW or by supplementing the basal diet with $1 \mathrm{~g}$ of QA $/ \mathrm{kg}$ (Vessal et al., 2003; Shetty et al., 2004). Quercetin has been shown to reduce glucose absorption in vitro at concentrations of $100 \mu M$ in Caco-2 cells by inhibition of sodium-independent glucose uptake (Johnston et al., 2005), and it has been shown that rats treated daily with $10 \mathrm{mg}$ of $\mathrm{QA} / \mathrm{kg}$ of BW over 10 $\mathrm{d}$ showed an increased number of pancreatic islets (Hii and Howell, 1985; Vessal et al., 2003). Further, addition of 10 and $100 \mu \mathrm{mol}$ of $\mathrm{QA} / \mathrm{L}$ enhanced insulin release in isolated pancreatic islets of rats (Hii and Howell, 1985), and quercetin and kaempferol $(50 \mu M)$ inhibited glucose-6-phosphatase activity in rat liver (Estrada et al., 2005), which might result in reduced blood glucose levels. However, we did not find significant alterations in plasma glucose or NEFA concentrations after administration of QA. This might be due to several factors. First, effects of quercetin in those studies were evaluated after a long-term dietary supplementation of at least $10 \mathrm{~d}$. Second, in the in vitro studies, comparatively high quercetin concentrations were used, which were not achieved in our in vivo study. Finally, in contrast to that in monogastrics, glucose supply in ruminants depends almost exclusively on gluconeogenesis; hence, impairment of glucose absorption will, if anything, have only minor consequences for plasma glucose concentrations (Bell and Bauman, 1997).

\section{CONCLUSIONS}

This study was the first to characterize the bioavailability of quercetin after duodenal administration in 
dairy cows. Bioavailability appeared to be within the range observed in monogastric species, and hence a rumen-protected quercetin formulation would be reasonable to avoid ruminal degradation of the flavonol. The data reported here, together with that of the companion paper (Berger et al., 2012), suggest that rutin could be one such rumen-protected form of quercetin. Although we calculated the half-life of total flavonols and quercetin in plasma, this does not necessarily reflect distribution in tissues. Because of the specific nature of this bioavailability study, metabolic data and data on performance warrant verification with longer term applications. In future studies, the diet-derived intake of flavonols should be estimated based on flavonoid analysis in feed.

\section{ACKNOWLEDGMENTS}

The authors are grateful to P. Schulz and M. Jürgensen (Institute for Animal Nutrition and Physiology, Christian-Albrechts-University of Kiel, Germany) as well as S. Dwars, K. Grot, C. Arlt, and S. Görs (Department of Nutritional Physiology "Oskar Kellner", Leibniz Institute for Farm Animal Biology) for excellent laboratory assistance. B. Stabenow and his team, and D. Oswald, C. Fiedler, K. Korinth, A. Schulz, and K. Pilz of the "Tiertechnikum" (Leibniz Institute for Farm Animal Biology; Department of Nutritional Physiology "Oskar Kellner") are gratefully acknowledged for assistance with animal care. F. Schultz (Rinderzuchtverband Meckenburg-Vorpommern, Woldegk, Germany) is acknowledged for assistance in selection of cows. This work is part of the joint research project Food Chain Plus (FoCus) and was financially supported by the Federal Ministry of Education and Research, Germany (BMFT grant no. 0315538B).

\section{REFERENCES}

Ader, P., A. Wessmann, and S. Wolffram. 2000. Bioavailability and metabolism of the flavonol quercetin in the pig. Free Radic. Biol. Med. 28:1056-1067.

Arts, I. C., A. L. Sesink, M. Faassen-Peters, and P. C. Hollmann. 2004. The type of sugar moiety is a major determinant of the small intestinal uptake and subsequent biliary excretion of dietary quercetin glycosides. Br. J. Nutr. 91:841-847.

Balcells, J., A. Aris, A. Serrano, A. R. Seradj, J. Crespo, and M. Devant. Effects of an extract of plant flavonoids (Bioflavex ${ }^{\circledR}$ ) on rumen fermentation and performance in heifers fed high-concentrate diets. J. Anim. Sci. http://dx.doi.org/10.2527/jas.20114955. (accepted)

Bell, A. W., and D. E. Bauman. 1997. Adaptations of glucose metabolism during pregnancy and lactation. J. Mammary Gland Biol. Neoplasia 2:265-278.

Berger, L. M., R. Blank, S. Wein, C. C. Metges, and S. Wolffram. 2012. Bioavailability of the flavonol quercetin in cows after intraruminal application of quercetin aglycone and rutin. J. Dairy Sci. 95:5047-5055.
Besle, J. M., D. Viala, B. Martin, P. Pradel, B. Meunier, J. L. Berdague, D. Fraisse, J. L. Lamaison, and J. B. Coulon. 2010. Ultraviolet-absorbing compounds in milk are related to forage polyphenols. J. Dairy Sci. 93:2846-2856.

Blaut, M., L. Schoefer, and A. Braune. 2003. Transformation of flavonoids by intestinal microorganisms. Int. J. Vitam. Nutr. Res. 73:79-87.

Cermak, R., and G. M. Breves. 2006. In vitro degradation of the flavonol quercetin and of quercetin glycosides in the porcine hindgut. Arch. Anim. Nutr. 60:180-189.

Cermak, R., S. Landgraf, and S. Wolffram. 2003. The bioavailability of quercetin in pigs depends on the glycoside moiety and on dietary factors. J. Nutr. 133:2802-2807.

Cheng, K. J., G. A. Jones, F. J. Simpson, and M. P. Bryant. 1969. Isolation and identification of rumen bacteria capable of anaerobic rutin degradation. Can. J. Microbiol. 15:1365-1371.

Colitti, M., and B. Stefanon. 2006. Effect of natural antioxidants on superoxide dismutase and glutathione peroxidase mRNA expression in leukocytes from periparturient dairy cows. Vet. Res. Commun. 30:19-27.

Cottica, S. M., S. C. de Aguiar, E. M. de Paula, R. B. Samensari, L. P. P. de Moura, S. L. Franco, J. V. Visentainer, G. T. dos Santos, R. Kazama, O. P. P. do Prado, F. J. Maia, and L. M. Zeoula. 2011. Antioxidant activity in milk of dairy cows fed diets containing propolis-based products. J. Dairy Sci. 94:621. (Abstr.)

Day, A. J., and G. Williamson. 2003. Absorption of quercetin glycosides. Pages 391-412 in Flavonoids in Health and Disease. 2nd ed. C. A. Rice-Evans and L. Packer, ed. CRC Press, Boca Raton, FL.

de Boer, V. C., A. A. Dihal, H. van der Woude, I. C. Arts, S. Wolffram, G. M. Alink, I. M. Rietjens, J. Keijer, and P. C. Hollman. 2005. Tissue distribution of quercetin in rats and pigs. J. Nutr. 135:1718-1725.

Egert, S., S. Wolffram, A. Bosy-Westphal, C. Boesch-Saadatmandi, A. E. Wagner, J. Frank, G. Rimbach, and M. J. Mueller. 2008. Daily quercetin supplementation dose-dependently increases plasma quercetin concentrations in healthy humans. J. Nutr. 138:16151621.

Estrada, O., M. Hasegawa, F. Gonzalez-Mujica, N. Motta, E. Perdomo, A. Solorzano, J. Mendez, B. Mendez, and E. G. Zea. 2005. Evaluation of flavonoids from Bauhinia megalandra leaves as inhibitors of glucose-6-phosphatase system. Phytother. Res. 19:859-863.

Fraisse, D., A. E. Carnat, D. Viala, P. Pradel, J. M. Besle, J. B. Coulon, C. Felgines, and J. L. Lamaison. 2007. Polyphenolic composition of a permanent pasture: Variations related to the period of harvesting. J. Sci. Food Agric. 87:2427-2435.

Frey, J. C., A. N. Pell, R. Berthiaume, H. Lapierre, S. Lee, J. K. Ha, J. E. Mendell, and E. R. Angert. 2010. Comparative studies of microbial populations in the rumen, duodenum, ileum and faeces of lactating dairy cows. J. Appl. Microbiol. 108:1982-1993.

GfE (German Society of Nutrition Physiology). 2001. Ausschuss für Bedarfsnormen der Gesellschaft für Ernährungsphysiologie, No. 8. Empfehlungen zur Energie- und Nährstoffversorgung der Milchkühe und Aufzuchtrinder (Recommended energy and nutrient supply for dairy cows and growing cattle). DLG-Verlag Frankfurt am Main, Germany.

GfE (German Society of Nutrition Physiology). 2009. New equations for predicting metabolisable energy of feed compound for cattle. Proc. Soc. Nutr. Physiol. 18:143-146.

Gladine, C., E. Rock, C. Morand, D. Bauchart, and D. Durand. 2007. Bioavailability and antioxidant capacity of plant extracts rich in polyphenols, given as a single acute dose, in sheep made highly susceptible to lipoperoxidation. Br. J. Nutr. 98:691-701.

Graefe, E. U., J. Wittig, S. Mueller, A. K. Riethling, B. Uehleke, B. Drewelow, H. Pforte, G. Jacobasch, H. Derendorf, and M. Veit. 2001. Pharmacokinetics and bioavailability of quercetin glycosides in humans. J. Clin. Pharmacol. 41:492-499.

Hertog, M. G. L., P. C. H. Hollman, and M. B. Katan. 1992. Content of potentially anticarcinogenic flavonoids of 28 vegetables and 9 fruits commonly consumed in the Netherlands. J. Agric. Food Chem. 40:2379-2383. 
Hii, C. S., and S. L. Howell. 1985. Effects of flavonoids on insulin secretion and $45 \mathrm{Ca}^{2+}$ handling in rat islets of Langerhans. J. Endocrinol. 107:1-8.

Hollman, P. C. H., M. N. C. P. Bijsman, Y. van Gameren, E. P. J. Cnossen, J. H. M. de Vries, and M. B. Katan. 1999. The sugar moiety is a major determinant of the absorption of dietary flavonoid glycosides in man. Free Radic. Res. 31:569-573.

Johnston, K., P. Sharp, M. Clifford, and L. Morgan. 2005. Dietary polyphenols decrease glucose uptake by human intestinal Caco-2 cells. FEBS Lett. 579:1653-1657.

Labib, S., A. Erb, M. Kraus, T. Wickert, and E. Richling. 2004. The pig caecum model: A suitable tool to study the intestinal metabolism of flavonoids. Mol. Nutr. Food Res. 48:326-332.

Lesser, S., R. Cermak, and S. Wolffram. 2004. Bioavailability of quercetin in pigs is influenced by the dietary fat content. J. Nutr. 134:1508-1511.

Lesser, S., and S. Wolffram. 2006. Oral bioavailability of the flavonol quercetin - A review. Curr. Top. Nutraceut. Res. 4:239-256.

Lin, Y.-T., S.-L. Hsiu, Y.-C. Hou, H.-Y. Chen, and P.-D. L. Chao. 2003. Degradation of flavonoid aglycones by rabbit, rat and human fecal flora. Biol. Pharm. Bull. 26:747-751.

Mambrini, M., and J. L. Peyraud. 1997. Retention time of feed particles and liquids in the stomachs and intestines of dairy cows. Direct measurement and calculations based on faecal collection. Reprod. Nutr. Dev. 37:427-442.

Manach, C., C. Morand, C. Demigne, O. Texier, F. Regerat, and C. Remesy. 1997. Bioavailability of rutin and quercetin in rats. FEBS Lett. 409:12-16.

Manach, C., A. Scalbert, C. Morand, C. Remesy, and L. Jimenez. 2004. Polyphenols: Food sources and bioavailability. Am. J. Clin. Nutr. 79:727-747.

Manach, C., G. Williamson, C. Morand, A. Scalbert, and C. Remesy. 2005. Bioavailability and bioefficacy of polyphenols in humans. I. Review of 97 bioavailability studies. Am. J. Clin. Nutr. 81(Suppl.):230S-242S.

Michelland, R. J., V. Monteils, A. Zened, S. Combes, L. Cauquil, T. Gidenne, J. Hamelin, and L. Fortun-Lamothe. 2009. Spatial and temporal variations of the bacterial community in the bovine digestive tract. J. Appl. Microbiol. 107:1642-1650.

Middleton, E. Jr., C. Kandaswami, and T. C. Theoharides. 2000. The effects of plant flavonoids on mammalian cells: Implications for inflammation, heart disease, and cancer. Pharmacol. Rev. 52:673751.

Movileanu, L., I. Neagoe, and M. L. Flonta. 2000. Interaction of the antioxidant flavonoid quercetin with planar lipid bilayers. Int. J. Pharm. 205:135-146.

Naumann, C., and R. Bassler. 1993. Method book III: The Chemical Analysis of Feedstuffs. VDLUFA-Verlag, Darmstadt, Germany.

O'Connell, J. E., and P. F. Fox. 2001. Significance and applications of phenolic compounds in the production and quality of milk and dairy products: A review. Int. Dairy J. 11:103-120.
Olthof, M. R., P. C. Hollman, T. B. Vree, and M. B. Katan. 2000. Bioavailabilities of quercetin-3-glucoside and quercetin-4'-glucoside do not differ in humans. J. Nutr. 130:1200-1203.

Pond, K. R., W. C. Ellis, J. H. Matis, H. M. Ferreiro, and J. D. Sutton. 1988. Compartment models for estimating attributes of digesta flow in cattle. Br. J. Nutr. 60:571-595.

Poore, M. H., J. A. Moore, T. P. Eck, and R. S. Swingle. 1991. Influence of passage model, sampling site, and marker dosing time on passage of rare earth-labeled grain through Holstein cows. J. Anim. Sci. 69:2646-2654.

Reinboth, M., S. Wolffram, G. Abraham, F. R. Ungemach, and R. Cermak. 2010. Oral bioavailability of quercetin from different quercetin glycosides in dogs. Br. J. Nutr. 104:198-203.

Reynaud, A., D. Fraisse, A. Cornu, A. Farruggia, E. Pujos-Guillot, J. M. Besle, B. Martin, J. L. Lamaison, D. Paquet, M. Doreau, and B. Graulet. 2010. Variation in content and composition of phenolic compounds in permanent pastures according to botanical variation. J. Agric. Food Chem. 58:5485-5494.

Rochfort, S., A. J. Parker, and F. R. Dunshea. 2008. Plant bioactives for ruminant health and productivity. Phytochemistry 69:299322

Schoefer, L., R. Mohan, A. Schwiertz, A. Braune, and M. Blaut. 2003. Anaerobic degradation of flavonoids by Clostridium orbiscindens. Appl. Environ. Microbiol. 69:5849-5854.

Shetty, A. K., R. Rashmi, M. G. R. Rajan, K. Sambaiah, and P. V. Salimath. 2004. Antidiabetic influence of quercetin in streptozotocininduced diabetic rats. Nutr. Res. 24:373-381.

Tedesco, D., A. Tava, S. Galletti, M. Tameni, G. Varisco, A. Costa, and S. Steidler. 2004. Effects of silymarin, a natural hepatoprotector, in periparturient dairy cows. J. Dairy Sci. 87:2239-2247.

Vessal, M., M. Hemmati, and M. Vasei. 2003. Antidiabetic effects of quercetin in streptozocin-induced diabetic rats. Comp. Biochem. Physiol. C Toxicol. Pharmacol. 135C:357-364.

Waghorn, G. C., and W. C. McNabb. 2003. Consequences of plant phenolic compounds for productivity and health of ruminants. Proc. Nutr. Soc. 62:383-392.

Walgren, R. A., U. K. Walle, and T. Walle. 1998. Transport of quercetin and its glucosides across human intestinal epithelial Caco-2 cells. Biochem. Pharmacol. 55:1721-1727.

Wang, Y., G. B. Douglas, G. C. Waghorn, T. N. Barry, and A. G. Foote. 1996. Effect of condensed tannins in Lotus corniculatus upon lactation performance in ewes. J. Agric. Sci. 126:353-362.

Wilfart, A., L. Montagne, H. Simmins, J. Noblet, and J. Milgen. 2007. Digesta transit in different segments of the gastrointestinal tract of pigs as affected by insoluble fibre supplied by wheat bran. Br. J. Nutr. 98:54-62. 